\title{
BMJ Open Improving quality in clinical placement studies in nursing homes (QUALinCLINstud): the study protocol of a participatory mixed-methods multiple case study design
}

\author{
Kristin Alstveit Laugaland (D) , ${ }^{1}$ Marianne Thorsen Gonzalez, ${ }^{2}$ \\ Brendan McCormack, ${ }^{3}$ Kirsti-Iren Skovdahl, ${ }^{4}$ Åshild Slettebø, ${ }^{5}$ Stephen Billett, ${ }^{6}$ \\ Kristin Akerjordet ${ }^{1}$
}

To cite: Laugaland KA, Gonzalez MT, McCormack B, et al. Improving quality in clinical placement studies in nursing homes (QUALinCLINstud): the study protocol of a participatory mixed-methods multiple case study design. BMJ Open 2020;10:e040491. doi:10.1136/ bmjopen-2020-040491

- Prepublication history for this paper is available online To view these files, please visit the journal online (http://dx.doi. org/10.1136/bmjopen-2020040491).

Received 14 May 2020 Revised 12 August 2020 Accepted 29 September 2020

Check for updates

(C) Author(s) (or their employer(s)) 2020. Re-use permitted under CC BY-NC. No commercial re-use. See rights and permissions. Published by BMJ.

For numbered affiliations see end of article.

Correspondence to Dr Kristin Alstveit Laugaland; kristin.a.laugaland@uis.no

\section{ABSTRACT}

Introduction Improved quality in clinical supervision and assessment of student nurses in nursing home clinical placements is vitally important to effective recruitment and preparation for this healthcare sector. Knowledge regarding supervision and assessment practices within these settings is limited. Also, knowledge of evolving elearning tools on the quality and effectiveness of these educational practices seems to be absent.

Methods and analysis The aim of the "Improving quality in clinical placement studies in nursing homes" (QUALinCLINstud) study is to develop and evaluate how a web-based programme can optimise supervision, assessment and learning during nursing home placements. The study applies a participatory, mixed-methods case study design, organised in four work packages (WPs). WP1 will explore how the nurse education institution address the quality of student nurses' clinical placements in nursing homes. In WP2, clinical supervision and assessment practices will be explored, and described from multiple stakeholder perspectives. In WP3, based on the findings from WP1 and WP2, a web-based pedagogical supervision and assessment programme will be developed through a developmental co-productive process between nurse education institutions, practice settings and student nurses. In WP4, the web-based programme will be pilot-tested and evaluated through a mixed-methods approach. A range of data collection procedures will be used throughout the project, for example, questionnaires, interviews, observations and workshops.

Ethics and dissemination The ethical conduct of the study is approved by the Norwegian Centre for Research Data (2018/61309 and 489776). The results will be disseminated through scientific articles, three $\mathrm{PhD}$ theses, presentations at national and international conferences, and through publicly accessible trade journals and newspapers. The results will generate knowledge to inform supervision and assessment practices in nursing home placements. Moreover, the study will generate knowledge concerning the developmental process of a web-based supervision and assessment programme, and the value of e-learning tools applied in clinical nursing education.
Strengths and limitations of this study

- The study will explore and describe current supervision and assessment practices from multiple stakeholder perspectives by applying methodological approaches that are novel in the field of nurse education research.

- The study will collect data from multiple nursing home settings thereby providing rich material permitting exploring context variability.

- A key strength of the 'QUALinCLINstud' study will be user involvement, co-production and collaboration between nurse education institutions, practice settings and students to support learning and develop innovative e-learning tools to enhance quality and efficiency in supervision and assessment practices of student nurses in nursing homes.

- The pilot-test group of the web-based supervision and assessment programme users will be limited, giving few possibilities for generalising results.

- The study will be set within Norwegian nurse education contexts and, thus, the generalisation of findings might be limited internationally. However, the 'thick descriptions' of the findings provided, and the project outputs will enable transferability and usability as determined by international stakeholders.

\section{INTRODUCTION}

Enabling nursing students to learn and develop clinical competence is the cornerstone of nursing education programmes. ${ }^{1}$ According to the Norwegian nursing curriculum and EU standards, 50\% (90 ECTS) of the bachelor education should comprise placements in the clinical field as learning environments. Consequently, this calls for high-quality learning environments in which clinical supervision and appropriate assessment strategies can optimise nursing students' learning and professional development. ${ }^{2-4}$ 
Despite these requirements, to date, relatively little attention has been given to nursing homes as learning environments and sites for clinical education placements. Yet, there is a need for nurse educators to more fully understand and engage nursing homes as clinical learning environments and make improvements to the quality of those experiences, where possible. ${ }^{5}$

All of this is important and urgent, as the number of older people in long-term care is increasing in Norway and worldwide, ${ }^{5}$ implying that professional competence in aged-care facilities will need to be redirected from hospitals to primary care institutions in the future. ${ }^{6}$ This societal re-prioritisation demands the need for highly qualified nursing staff working in nursing homes. The need for nursing competence is also increasing and the expected shortage of nurses with advanced degrees in caring for older people or gerontology needs to be addressed. ${ }^{5}$ However, previous studies report that student nurses view caring for older people as a negative and unattractive career choice in boring and depressing nursing home contexts. ${ }^{78}$ The poor quality of clinically situated learning and supervision is also reported having a direct and negative impact on student nurses' learning, career ambitions and overall perceptions of nursing work. ${ }^{9}$ Together, these two factors make it difficult to attract and prepare competent aged-care nurses.

The quality of clinical supervision and assessment has a significant impact on student nurses' development and learning. ${ }^{34}$ A supportive clinical learning environment is held to be crucial for student learning and to their development as reflective and competent nursing practitioners able to engage effectively in critical clinical reasoning and decision-making in their practice. ${ }^{10}$ Critical thinking is an essential capacity for safe, effective and skilled clinical nursing, and there is a need for nurse educators to intentionally promote critical thinking and clinical reasoning skills. ${ }^{11}$ Learning during clinical placement is influenced by a range of factors, such as well-planned orientation, and welcoming of students as member of staff in the clinical learning environment. ${ }^{12}$ However, the supervisory relationship and the role of mentors is essential. ${ }^{13}$ The effective mentoring of less experienced workers and students is an integral part of nurses' work. ${ }^{14}$ Mentors are usually senior nursing staff and expected to act as role models and counsellors for students during their clinical placements. ${ }^{15}$ Hence, mentors have many roles including advisor, supporter, evaluator, influencer, eye-opener, door-opener, problem-solver, challenger and career counsellor. ${ }^{15} 16$ Mentors are required to have sufficient abilities, and complex personal and pedagogical qualities and competencies, but they often report feeling inadequate and insecure when taking on the mentor role. ${ }^{17}$ The importance of mentors' ability to supervise as well as assess their mentees' competence is emphasised. ${ }^{418} 19$

A recent systematic review ${ }^{4}$ identified substantial variations in assessment practices internationally, suggesting that the assessment practices of student nurses in clinical placement studies lack reliability. Some researchers argue that reliable and comparable assessment of student nurses' knowledge and skill requires the development of national assessment tools. ${ }^{320}$ A variety of tools currently exist for assessing student performance in clinical placements. ${ }^{4}{ }^{21}$ However, nurse mentors report experiencing difficulties in establishing effective relationships with students, providing feedback and assessing their competence due to absence of clear assessment criteria. ${ }^{4}$ This absence creates difficulties in making valid and reliable assessment of students' competence and skills and further complicates mentors' abilities to help students bridge the gap between theory and clinical experiences. ${ }^{22}$ The importance of structured assessment tools guiding nurse mentors in the assessment process is frequently emphasised. ${ }^{41}$ However, research has identified mentors' difficulties in understanding the language of forms for assessing student nurses' clinical performance. Yet, clinical assessments need to accommodate the multidimensional nature of clinical competence and the range of attributes required for professional practice. ${ }^{23}$ So, to foster supportive clinical learning environments, nurse mentors should be offered consistent and focused education to enhance their competencies in supervision and assessment practices. ${ }^{4}$ Hence, there is a need to develop and explore education interventions aimed at improving mentors' competencies in clinical supervision and assessment. ${ }^{4}$

Nursing homes can be excellent learning environments, offering learning experiences of caring for a frail older population with multiple health comorbidities. Such learning situations are not easily found elsewhere, and they exemplify the practice of registered nursing. To support nursing homes in being optimal clinical placement experiences, there is a need for effective partnerships between the higher education institution (HEI) and the nursing home, where clinical learning and supervision address students' learning needs while providing safe and effective care. ${ }^{24-26}$ This partnership is important, as there is often a mismatch between the number of students in need of clinical supervision and assessment and the number of available registered nurse mentors, especially in primary care settings. ${ }^{132}$

To address this mismatch, fresh approaches involving information and communication technologies offering new possibilities for optimising supervision and assessment of student nurses in clinical placements are evolving. ${ }^{28}{ }^{29}$ For instance, Mettiäinen ${ }^{30}$ reports that a software assessment and feedback tool aided nurse educators' clinical supervision by visually representing students' daily work and thereby assisting in identifying their need for support. This also helped structure the student's and the teacher's final assessment discussion. Student nurses in a study by Lai and $\mathrm{Wu}^{31}$ report substantial improvements in nursing skills and critical thinking from clinical nursing studies in a web-based learning environment, which also allowed mentors to provide the students with individualised supervision. Hence, these kinds of tools seem well aligned with addressing the identified issues faced by clinical supervisors and students on placements in clinical settings such as aged-care homes, where nurse staffing ratios may be low. There is, however, a need to assess the quality and effectiveness of these teaching and 
educational procedures. ${ }^{28} 29$ This is the main aim of the 'QUALinCLINstud' project.

\section{AIMS}

Considering the current challenges and knowledge gaps, the 'QUALinCLINstud' project has three objectives. These are to:

1. Explore how the HEI address high-quality learning environments, supervision and assessment of first-year student nurses in nursing home placements.

2. Explore current clinical supervision and assessment practices from a multiple stakeholder perspective.

3. Develop, pilot-test and evaluate an innovative webbased pedagogical supervision and assessment programme targeting quality in clinical supervision and assessment of first-year student nurses in nursing home placements.

Given the multiple stakeholders and complexity of issues involved in clinical supervision and assessment practices, the web-based programme will target three stakeholder groups: (1) nurse mentors, (2) first-year student nurses and (3) nurse educators. The web-based programme aims to improve the following quality dimensions: (1) nurse mentors' supervision and assessment competence; (2) student nurses' critical thinking skills and learning experience; and (3) efficiency in supervision and assessment practices. Thus, the innovation will incorporate and develop e-learning and education tools that are applicable to multiple perspectives in clinical placements compared with the single perspectives that is often adopted. ${ }^{32}$

A web-based programme using digital education tools may enhance the nurse mentors' supervision and assessment competencies, which are considered crucial in establishing a supportive clinical learning environment. ${ }^{4}$ Effective e-learning tools aim to enhance student nurses' critical thinking strategies required for their development as reflective practitioners, which is essential for safe, effective and skilled nursing practice. Utilisation of a webbased programme and digital tools have the potential to provide nurse educators with supervision approaches in order to supervise and monitor many students concurrently, while simultaneously monitoring these students' clinical learning processes during their placements. The web-based programme can also make students' learning achievements more transparent for educators. Figure 1 illustrates the content and quality dimensions of the webbased programme.

\section{METHODOLOGY}

\section{Design}

The QUALinCLINstud project (June 2018-December 2022) employs an explorative and descriptive multiple case study design ${ }^{33}$ using a mixed-methods approach and incorporating the methodology of participatory design (PD) ${ }^{34}$ This approach ensures that the development of

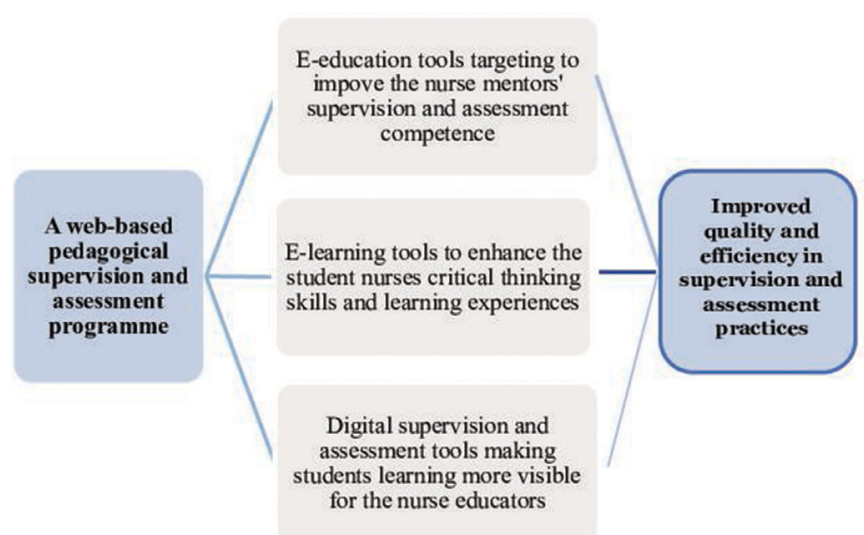

Figure 1 Content and quality dimensions of the web-based programme.

the web-based supervision and assessment programme is anchored in the experiences of key stakeholders. Hence, this study is underpinned by the idea that implementation of research-based knowledge is a social process where the creators and the users of knowledge collectively determine its appropriateness in supporting nursing student clinical placements. ${ }^{35}$

\section{Research settings}

The study settings are three HEIs in Norway and nursing homes as clinical placement sites in a range of municipalities. A case consists of one HEI along with the nursing homes it engages with to provide clinical placements to its students. Three cases are selected to provide comparisons across geographical areas and differently ranked education institutions. ${ }^{36}$

A multiple case sampling strategy will be applied consistent with the methodology of embedded case study design. ${ }^{33}$ The embedded case study design highlights that single cases (ie, A, B and C) potentially involve several units and subunits of analysis (eg, nursing homes, wards, perspectives). Based on the annual student evaluations in Norwegian higher education, the three cases have quite different scores. Cases A and B represent HEIs with low ratings in the Norwegian quality ranking while case C represents a HEI that was highly ranked on the same listing and, thus, considered a 'Best Practice' institution as a benchmark. ${ }^{37}$ The aims of the case study research design are threefold: (1) to explore the phenomenon of supervision and assessment in clinical education in nursing homes; (2) to appraise each case as a stand-alone entity, allowing for unique patterns of data to emerge from each case; and (3) to conduct cross-case comparison, identifying patterns of findings across the cases (eg, similarities and differences).

\section{Research strategies and data collection methods}

The study is structured across four sequential work packages (WPs) enacting distinct project phases. In the following section, the work packages, data collection, sources and data analysis are described and justified. 
WP1: Exploring quality in clinical education in nursing home placements

WP1 comprises an exploratory study of how the nurse education institution addresses quality in clinical education in nursing home placements. The specific questions this WP investigates are:

(a) How do the HEIs address the quality of clinical supervision and assessment (eg, professional competence in mentorship, assessment tools and strategies, students' critical thinking skills and learning experiences) of first-year student nurses in nursing home placements?

(b) How do the HEIs promote academic-practice partnerships for clinical supervision and assessment practices in nursing home placements?

(c) What characterises the learning activities, supervision strategies and assessment tools used by the nurse education system in nursing home placements?

(d) How do first-year student nurses report their satisfaction with nursing homes as clinical learning environments?

In WP1, data will be elicited through qualitative and quantitative procedures. Qualitative data will be collected through individual interviews with nurse educators in each of the three case-study settings (ie, HEI settings). A semi-structured interview guide will be developed, piloted, trialled and implemented to assist validity and reliability. A user panel, involving secondyear and third-year student nurses, nurse mentors and nurse educators, will be established. This panel will assist in ensuring the relevance and feasibility of the interview guide prior to data collection (ie, its piloting and trialling). The panel will also advise about the analysis of the data and review tentative findings to confirm and inform the findings and deductions. For the quantitative approach, a cross-sectional survey will be applied, where data will be collected across the three case study settings (ie, HEI settings) using the Norwegian version of the Clinical Learning Environment, Supervision and Nurse educator evaluation scale (CLES+T) ${ }^{38}$ CLES+T is a validated scale designed to measure and assess nursing students' satisfaction with the clinical learning environment, including clinical supervision in nursing home placements. Data from WP1 will be collected and analysed to address the particular research questions, providing results from both nurse educator and student perspectives. The qualitative interview data will be analysed using thematic analysis, ${ }^{39}$ a flexible approach that searches for themes within individual datasets as well as within and across case study sites. The quantitative survey data will be analysed using various descriptive and bivariate statistics using parametric or non-parametric tests depending on distribution of data (eg, independent t-test, Mann-Whitney U test). Data will be analysed using SPSS (latest version).
WP2: Exploring clinical supervision and assessment practices in nursing home placements

WP2 will explore the clinical supervision and assessment practices from multiple stakeholder perspectives. The research questions that shape WP2 are:

(e) What characterises clinical supervision and assessment practices of student nurses in nursing home placements?

(f) What are the key stakeholders' (ie, nurse mentors, first-year student nurses, nurse educators) experiences, feedback and recommendations about clinical supervision and assessment practices of student nurses in nursing home placements?

In this work package, a qualitative approach will be applied in which data will be collected through observations and interviews. Observations informed by ethnographic methods and procedures constitute the primary data source. To date, only a limited number of studies have applied observational research to illuminate the context and processes of supervision and assessment in nursing students' clinical placements. The observational data will be supplemented by individual interviews with key stakeholders (ie, student nurses, nurse mentors, nurse educators). WP2 involves data collection across the three case study sites (ie, HEIs and associated nursing homes).

The observations will be conducted during the students' nursing home placements and will comprise 1 day of weekly observation in the nursing home setting during the placement period (8-12 weeks). The observation study will employ moderate participant observations, allowing the researcher, who will be a registered nurse, to be present and identifiable, however, not actively participating (ie, with no role in the social setting), observing and interacting occasionally. ${ }^{40}$ In addition, observations will be conducted during the nurse educators' orientation meeting, midterm and final assessment of the student nurses' clinical performances during their placement period. An observation guide will be developed based on input from the user panel (ie, students, nurse mentors and nurse educators) and the literature. Themes in the observation guide will include, but not limited to, (1) models of supervision, (2) assessment strategies, (3) learning tools, (4) contextual factors and (5) learning environment. Individual interviews will be conducted soon after the clinical placement with key stakeholders (ie, first-year student nurses, nurse educators, nurse mentors) to appraise the qualities of their learning experiences and advance recommendations about enhancing clinical supervision and assessment practices. A semistructured interview guide will be developed based on findings from WP1, findings from field experience and relevant literature to aid validity and reliability. In addition, the user panel established in WP1 will participate in the development and validation of the data collection tools, practical planning of the data gathering processes and in analysing data. Three meetings will be held with the user panel (ie, prior to data collection, during data collection and during data analysis). Observations will 
be conducted during stakeholder meetings with the user panel to illuminate and explore the processes, benefits and challenges of stakeholder engagement.

The number of interviews undertaken with key stakeholders will be based on the principles of data saturation ${ }^{41}$ (ie, the number of interviews will be based on achieving an accumulation of data, but not unhelpful repetition). A preliminary estimate is to conduct 15 interviews in each case (totalling 45 interviews) distributed across the various stakeholders (ie, student nurses, nurse mentors, nurse educators). Observational data offer a rich, detailed platform for illuminating clinical supervision practices in nursing home placements that should lead to informed understandings. Observational procedures facilitate the study of clinical supervision and assessment as it is performed, as opposed to how these practices are conceived. In addition, comprehensive accounts of key stakeholder perspectives should provide valuable inputs, illuminating strengths and weaknesses in clinical supervision and assessment practices for student nurses, and assist in bringing about improvements.

The different datasets (eg, observations and interviews) will initially be analysed separately. ${ }^{42}$ Qualitative content analysis ${ }^{43}$ will be used to structure both datasets. These analyses involve creating meaning units, codes, categories and themes from those data. NVivo software will be used to structure, organise and correlate the analyses of the observations and interview transcripts. Data will be analysed both within and across the three case study sites (ie, HEIs and associated nursing homes). The findings from the observations (eg, core component) and interviews (eg, supplementary component) will be subsequently compared, contrasted and combined to achieve a synthesis across the qualitative datasets. ${ }^{42}$ To ensure trustworthiness in the analysis, triangulation and member checks will be applied. ${ }^{44}$

\section{WP3: Development of a web-based pedagogical supervision and assessment programme}

WP3 comprises developing the web-based pedagogical supervision and assessment programme targeting quality dimensions in nursing home placements. The specific research questions WP3 investigates are:

(g) What characterises key stakeholders' collaborative process in developing a web-based supervision and assessment programme targeting quality dimensions in nursing home placements?

(h) What are the core components of a web-based supervision and assessment programme targeting quality dimensions in clinical placements in nursing homes?

(i) What are the key stakeholders' (ie, nurse mentors, first-year student nurses, nurse educators, webdesigners) experiences of user involvement in design of a web-based supervision and assessment programme for use in clinical placements in nursing education?

(j) How can e-learning and educational tools be used to improve quality in clinical supervision and assess-

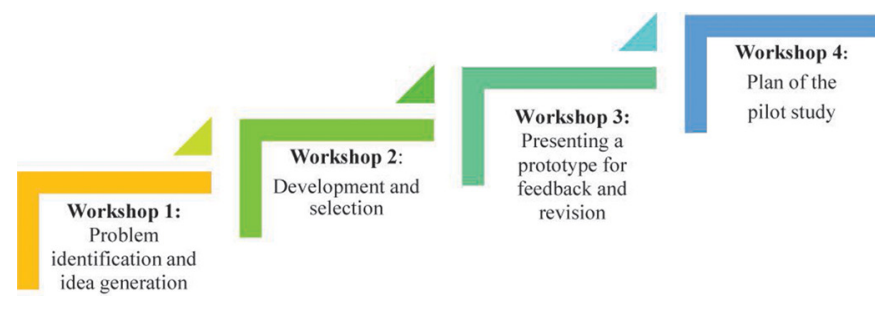

Figure 2 Planned workshops during the year of development.

ment of student nurses in clinical placements in the nursing homes context?

In WP3, the web-based supervision and assessment programme will be developed iteratively. The process of programme development will be informed and guided by a tentative synthesis of first impression findings from WP1 and WP2 and in close collaboration with key stakeholders and e-learning designers requiring an extension of the user panel established in WP1. The developmental process entails that the design, learning activities and content in the web- based programme will be co-produced with students, teachers, nurse mentors, e-learning designers and researchers. The co-production process will try to ensure that the programme meets stakeholders' needs, user interface and provides benefits in use. ${ }^{45}$ Workshops and dialogue meetings will be used as the main co-creation activities. In addition, content validity of the programme will be obtained through discussions with nurse experts (ie, collaborative partners, advisory board) with reference to the national standard for nursing competency and established academic nursing literature. Four workshops are planned during the year-long development period as illustrated in figure 2. This figure illustrates that each of the workshops has a distinct role and that these are iterative in developing the programme.

The first workshop will focus on problem identification and idea generation based on the stakeholders' experienced challenges concerning supervision and assessment in nursing home placements and suggestions for improvements. The tentative synthesis of findings from WP1 and WP2 will be presented to the different stakeholder groups at the first workshop with the purpose of comparing, complementing and further building identified problem areas and improvement measures. Between the first and second workshops, the research team will collaborate with the e-learning designers to suggest solutions to the identified problem areas and present responses and discuss these at the second workshop. In the third workshop, the research team will present a prototype of the web-based programme (ie, design and content) and receive feedback and inputs for further improvements. The fourth and final workshop will focus on planning the pilot study. In addition to developing the web-based programme, we are also concerned with mapping and appraising the co-production development process. To do this, observations will be conducted during the workshops to explore the degree of participation, involvement 
and group interactions. Furthermore, we will conduct focus group interviews with the key stakeholder participants to explore their views and experiences concerning involvement throughout the process of developing educational e-learning tools to optimise learning in clinical placements in nursing homes. Qualitative content analysis ${ }^{43}$ will be used to categorise data from focus group interviews (eg, core components) and the observation notes (eg, supplementary components). The datasets will be analysed separately prior to being combined and integrated in generating and advancing key findings. ${ }^{42}$ NVivo software will be used to structure, organise and correlate the analyses of the focus group interviews and the observations.

\section{WP4: To pilot-test and evaluate the web-based pedagogical supervision and assessment programme}

The aim of the project's final stage is to pilot-test, explore and describe the outcomes and usefulness of the webbased supervision and assessment programme developed and validated in WPs 1-3. The specific research questions in WP4 are:

(k) What are the differences in satisfaction with the learning environment between first-year student nurses being offered a web-based supervision and assessment programme and students that were not offered this programme?

(1) What are the first-year student nurses' experiences of learning and critical thinking skills when being offered a web-based supervision and assessment programme?

(m) What are the experiences and evaluations of nurse mentorship competence related to a web-based supervision and assessment programme?

(n) What are the experiences and evaluations in nurse educators' assessment practices based on the use of a web-based supervision and assessment programme?

(o) How do the stakeholders experience and evaluate the usefulness of a web-based supervision and assessment programme for student nurses when in nursing home placements?

(p) What are the success criteria and barriers in the implementation of a web-based supervision and assessment programme in nursing home placements?

In WP4, the pilot-testing and evaluation of the webbased supervision and assessment programme will use a mixed-methods convergent parallel design ${ }^{46}$ in two of the three case-study settings (cases A and B). The quantitative approach will pilot-test the web-based programme by using a comparative design addressing first-year bachelor student nurses as the target group. Eight nursing homes that did not participate in WPs 1-3 will be included. Of these eight nursing homes, four will be a part of case A and four to case B. In both cases, two nursing homes will constitute the intervention group (IG), and two anticipated similar nursing homes will constitute the control group (CG) and will not be offered the web-based programme. In total, 60 students will be included in the
IG and 60 students will act as a CG. Nursing students' satisfaction with clinical learning will be measured with the Norwegian version of the CLES+T. ${ }^{38}$ Data from both the IG and the CG from WP4 will be compared with data at a nursing home level from WP1.

The qualitative approach will address the usefulness of the web-based programme and data will be collected using individual and focus group interviews with the pilot group participants (ie, nurse educators, nursing students, nurse mentors). This approach will, thereby, explore and describe stakeholders' experiences of the programme's effectiveness according to targeted quality dimensions: (1) nurse mentors' supervision and assessment competence; (2) nurse students' critical thinking skills and learning experience; and (3) efficiency in supervision and assessment practices. In addition, observations will be conducted during the pilot-test period to assess success criteria and barriers in implementation of the webbased programme. The evaluation data will also include students' self-assessment documents aiming to explore and describe their use of critical thinking skills. In WP4, the quantitative and the qualitative data will be simultaneously collected and initially analysed separately. ${ }^{46}$ The quantitative data from the survey will be analysed using descriptive and comparative statistics (SPSS latest version) to explore differences in satisfaction with the learning environment between students being offered the web-based supervision and assessment programme and students not being offered the programme. The qualitative datasets (ie, focus group interviews, observations, student's self-assessment documents) will be analysed using qualitative content analysis ${ }^{43}$ to explore the stakeholders' experienced usefulness of the programme according to the targeted quality dimensions. All data will be analysed within and across the two case study pilot settings (cases A and B). Finally, the findings from the various datasets (ie, qualitative and quantitative) will be merged and synthesised applying the procedure labelled "joint display of data" ${ }^{46}$ to evaluate the overall success and effectiveness of the web-based programme incorporating results from the various stakeholders.

Figure 3 illustrates and summarises the distinct WPs in the QUALinCLINstud project.

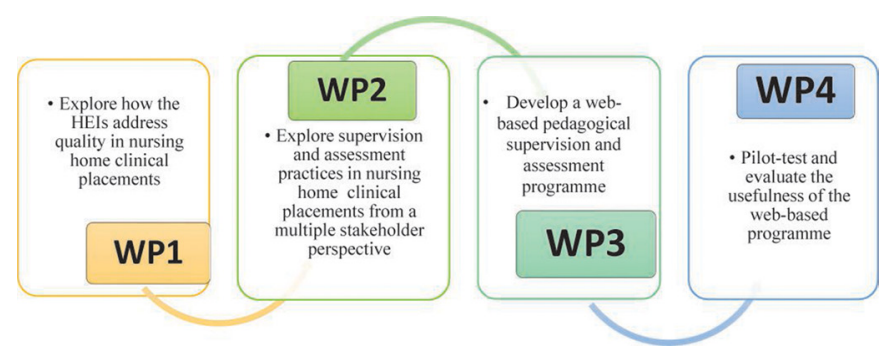

Figure 3 Summarising the distinct work packages in the 'QUALinCLINstud' project. HEI, higher education institution; WP, work package. 


\section{User involvement}

User involvement underpins the whole project, is included in all stages of the research and is considered vital to the overall success of the 'QUALinCLINstud' project. To address user involvement at an early stage, directors and leaders from two nursing homes have reviewed the project's suitability and sustainability and have found that the project goals and processes will be relevant and important. These stakeholders represent nursing homes that have been recruited as collaborative partners. Moreover, user involvement is ensured by recruitment of two registered nurses as part-time co-researchers for the entire project period. In addition, user panels with key stakeholders (ie, nurse educators, student nurses, nurse mentors) have been established to ensure active involvement and consultation. Dialogue meetings and workshops with stakeholders are held regularly as part of the project development process.

\section{Patient and public involvement}

No patients involved.

\section{ETHICS AND DISSEMINATION \\ Ethical reflections}

The study is approved by the Norwegian Centre for Research Data (2018/61309 and 489776). Since no health information or patient data will be registered during this research project, it falls outside the mandate of the Norwegian Regional Committees for Medical and Health Research Ethics. However, the proposed project follows the current ethical guidelines for good practice in research and education. All project participants will be recruited on a voluntary basis and informed consent will be obtained. All data will be anonymised and securely stored.

\section{Dissemination}

The 'QUALinCLINstud' partners have agreed publication guidelines, a publication strategy and a publication plan. The publication strategy consists of dissemination in recognised peer-reviewed scientific journals (17 publications), academic conferences, popular scientific journals, newspapers and directly to the users. Furthermore, the project has established a web page for the research project, which will be updated and from where we will communicate the results to the public, potential users, media and other researchers. We view nursing homes, nurse mentors, nursing students, nurse educators and HEIs as important users of our research. The 'QUALinCLINstud' partners will present at seminars and conferences organised by or targeting these stakeholders and institutions. The project has an international expert advisory board with members from the UK, Australia, Sweden and Denmark. The advisory board will be invited annually to provide input to the study and contribute to the sharing of results. The publication plan will evolve over time, but includes the following planned scientific dissemination activities:

- Three PhD theses.
- Seventeen scientific articles in different peer-reviewed journals.

- Local seminars, presentations and discussions at the study sites.

- Presentations at regional, national and international conferences.

- Popular Science presentations in national media.

Finally, if the investigation reveals that the web-based supervision and assessment programme is evaluated as useful, we will organise a national conference to which nurse educators will be invited and where the innovation will be presented, critical feedback encouraged, ideas discussed and possible cooperation for further improvements established.

\section{Author affiliations}

${ }^{1}$ SHARE-Centre for Resilience in Healthcare, Faculty of Health Sciences, University of Stavanger, Stavanger, Norway

${ }^{2}$ Faculty of Health and Social Sciences, University of South-Eastern NorwayCampus Drammen, Drammen, Buskerud, Norway

${ }^{3}$ School of Health Sciences, Queen Margaret University, Edinburgh, UK

${ }^{4}$ Faculty of Health Sciences, University of South-Eastern Norway-Campus

Drammen, Drammen, Buskerud, Norway

${ }^{5}$ Department of Health and Nursing Sciences, Faculty of Health and Sport Sciences, University of Agder, Grimstad, Norway

${ }^{6}$ School of Education and Professional Studies, Griffith University, Mount Gravatt, Queensland, Australia

Correction notice This article has been corrected since it was published. Twitter Brendan McCormack @Profbrendan

Acknowledgements We wish to acknowledge the contribution from Anne Marie Lunde Husebø who provided valuable inputs in developing the grant application to the Research Council of Norway (RCN). We also wish to acknowledge the members of the advisory board: Annica Khilgren (Sweden), Brendan McCormack (UK), Linda Lundgaard Andersen (Denmark), Stephen Billett (Australia) and Patrick Crookes (Australia). The authors would also like to thank the reviewers for valuable comments and input to improve the 'QUALinCLINstud' study protocol.

Contributors KAL, MTG and KA developed the original proposal for grant application and together with K-IS and ÅS applied for funding of the 'QUALinCLINstud' study to the Research Council of Norway (RCN). KAL drafted the manuscript and revised it based on comments from all the authors. MTG, $\mathrm{BM}, \mathrm{SB}$ and KA contributed to the drafting and revision of the manuscript. $\mathrm{K}$-IS and ÅS commented on the original proposal for grant application and commented on the draft. All authors approved the final version of the manuscript.

Funding This work is supported by The Research Council of Norway (RCN) grant number 273558 and by the University of Stavanger, the University of South-Eastern Norway and the University of Agder.

Competing interests None declared.

Patient consent for publication Not required.

Ethics approval The 'QUALinCLINstud' project is approved by the Norwegian Centre for Research Data (2018/61309 and 489776) and exempted from ethical approval from the Norwegian Regional Committees for Medical and Health Research Ethics.

Provenance and peer review Not commissioned; externally peer reviewed.

Open access This is an open access article distributed in accordance with the Creative Commons Attribution Non Commercial (CC BY-NC 4.0) license, which permits others to distribute, remix, adapt, build upon this work non-commercially, and license their derivative works on different terms, provided the original work is properly cited, appropriate credit is given, any changes made indicated, and the use is non-commercial. See: http://creativecommons.org/licenses/by-nc/4.0/.

ORCID iD

Kristin Alstveit Laugaland http://orcid.org/0000-0003-3451-2584 


\section{REFERENCES}

1 Rush S, Firth T, Burke L, et al. Implementation and evaluation of peer assessment of clinical skills for first year student nurses. Nurse Educ Pract 2012;12:219-26.

2 Helminen K, Coco K, Johnson M, et al. Summative assessment of clinical practice of student nurses: a review of the literature. Int $J$ Nurs Stud 2016;53:308-19.

3 Newton L, Pront L, Giles TM. Experiences of registered nurses who supervise international nursing students in the clinical and classroom setting: an integrative literature review. J Clin Nurs 2016;25:1486-500.

4 Immonen $\mathrm{K}$, Oikarainen A, Tomietto M, et al. Assessment of nursing students' competence in clinical practice: a systematic review of reviews. Int J Nurs Stud 2019;100:103414.

5 Cheng M, Cheng C, Tian Y, et al. Student nurses' motivation to choose gerontological nursing as a career in China: a survey study. Nurse Educ Today 2015;35:843-8.

6 St.meld. nr. 47. Samhandlingsreformen. Rett behandling - på rett sted - til rett tid. [Report No. 47 (2008-2009) to the Storting. The Coordination Reform. Proper treatment - at the right place and right time]. Oslo: Helse- og omsorgsdepartementet; 2008-2009. Available: https://www.regjeringen.no/no/dokumenter/stmeld-nr-47-20082009-/id567201/ [in Norwegian] [Accessed 72020 May]

7 McCann TV, Clark E, Lu S. Bachelor of nursing students career choices: a three-year longitudinal study. Nurse Educ Today 2010;30:31-6.

8 Stevens JA. Student nurses' career preferences for working with older people: a replicated longitudinal survey. Int J Nurs Stud 2011;48:944-51.

9 Koskinen S, Hupli M, Katajisto J, et al. Graduating Finnish nurse students' interest in gerontological nursing - a survey study. Nurse Educ Today 2012;32:356-60.

10 Birks M, Bagley T, Park T, et al. The impact of clinical placement model of learning in nursing: a descriptive exploratory study. Australian Journal of Advanced Nursing 2017;34:16-23.

11 Papathanasiou IV, Kleisiaris CF, Fradelos EC, et al. Critical thinking: the development of an essential skill for nursing students. Acta Inform Med 2014;22:283-6.

12 Bisholt B, Ohlsson U, Engström AK, et al. Nursing students' assessment of the learning environment in different clinical settings. Nurse Educ Pract 2014;14:304-10.

13 Husebø AML, Storm M, Våga BB, et al. Status of knowledge on student-learning environments in nursing homes: a mixed-method systematic review. J Clin Nurs 2018;27:e1344-59.

14 Kinnell D. Mentoring nursing and healthcare students. In: Kinnell D, Hughes P, eds. Mentoring nursing and healthcare students. United Kingdom: SAGE Publication Ltd, Cornwall, 2010: 2010. 7-30.

15 Walsh D. The nurse mentor's handbook. Supporting students in clinical practice. United Kingdom: Open University Press. McGrawHill. Bell and Bain Ltd, 2010.

16 Gopee N. Mentoring and supervision in healthcare. 2nd Edition. CPI Antony Rowe, Chippenham, Wiltshire: SAGE Publication Ltd, 2011.

17 Bos E, Silen C, Kaila P. Clinical supervision in primary health care; experiences of distinct nurses as clinical supervisors-a qualitative study. BMC Nursing 2015;39.

18 Dale B, Leland A, Dale JG. What factors facilitate good learning experiences in clinical studies in nursing: bachelor students' perceptions. ISRN Nurs 2013;2013:1-7.

19 Papastavrou E, Dimitriadou M, Tsangari H, et al. Nursing students' satisfaction of the clinical learning environment: a research study. BMC Nurs 2016;15:44.

20 Cassidy I, Butler MP, Quillinan B, et al. Preceptors' views of assessing nursing students using a competency based approach. Nurse Educ Pract 2012;12:346-51.

21 Wu XV, Enskär K, Lee CCS, et al. A systematic review of clinical assessment for undergraduate nursing students. Nurse Educ Today 2015;35:347-59.
22 Fotheringham D. Triangulation for the assessment of clinical nursing skills: a review of theory, use and methodology. Int J Nurs Stud 2010;47:386-91.

23 Levett-Jones T, Gersbach J, Arthur C, et al. Implementing a clinical competency assessment model that promotes critical reflection and ensures nursing graduates' readiness for professional practice. Nurse Educ Pract 2011:11:64-9.

24 Carlson E, Bengtsson M. The uniqueness of elderly care: registered nurses' experience as preceptors during clinical practice in nursing homes and home-based care. Nurse Educ Today 2014;34:569-73.

25 Brynildsen G, Bjørk IT, Berntsen K, et al. Improving the quality of nursing students' clinical placements in nursing homes: an evaluation study. Nurse Educ Pract 2014;14:722-8.

26 Algoso M, Peters K, Ramjan L, et al. Exploring undergraduate nursing students' perceptions of working in aged care settings: a review of the literature. Nurse Educ Today 2016;36:275-80.

27 Barnett T, Cross M, Jacob E, et al. Building capacity for the clinical placement of nursing students. Collegian 2008;15:55-61.

28 McCutcheon K, Lohan M, Traynor M, et al. A systematic review evaluating the impact of online or blended learning vs. face-to-face learning of clinical skills in undergraduate nurse education. J Adv Nurs 2015;71:255-70.

29 O'Connor S, Andrews T. Smartphones and mobile applications (apps) in clinical nursing education: a student perspective. Nurse Educ Today 2018;69:172-8.

30 Mettiäinen S. Electronic assessment and feedback tool in supervision of nursing students during clinical training. Electronic Journal of eLearning 2015;13:42-56.

31 Lai C-Y, Wu C-C. Supporting nursing students' critical thinking with a mobile web learning environment. Nurse Educ 2012;37:235-6.

32 Courtney-Pratt H, Fitzgerald M, Ford K, et al. Development and reliability testing of the quality clinical placement evaluation tool. $J$ Clin Nurs 2014;23:504-14.

33 Yin K. Case study research design and methods. In: Applied social research methods series. Fifth edition. SAGA Publication, 2014.

34 Sanoff H. Multiple views of participatory design. Focus 2008;8 (1), Article 7.

35 Dopson S, Fitzgerald L. Knowledge to action? Evidence-based health care in context. Oxford University Press, 2015.

36 Miles MB, Huberman MA. Qualitative data analysis. Second ed. Saga Publication, 1994.

37 NOKUT. The Norwegian agency for quality assurance in education. Available: http://www.studiebarometeret.no/no

38 Henriksen N, Normann HK, Skaalvik MW. Development and testing of the Norwegian version of the clinical learning environment, supervision and nurse teacher (CLES+T) evaluation scale. Int $J$ Nurs Educ Scholarsh 2012;9. doi:10.1515/1548-923X.2239. [Epub ahead of print: 18 Sep 2012].

39 Braun V, Clarke V. Using thematic analysis in psychology. Qual Res Psychol 2006;3:77-101.

40 DeWalt KM, DeWalt BR. Participant observation: a guide for fieldworkers. Alta Mira Press, 2011

41 Polit DF, Beck CT. Nursing research. In: Principles and methods. Eighth ed. Lippincott Williams \& Wilkins, 2008.

42 Morse MJ, Niehaus L. Mixed method design. In: Principles and procedures. Routledge, 2016.

43 Graneheim UH, Lundman B. Qualitative content analysis in nursing research: concepts, procedures and measures to achieve trustworthiness. Nurse Educ Today 2004;24:105-12.

44 Hammersly M A. Ethnography: principles in practice. Routledge, 2007.

45 Dollinger M, Lodge J, Coates $\mathrm{H}$. Co-creation in higher education: towards a conceptual model. Journal of Marketing for Higher Education 2018;28:210-31.

46 Cresswell WJ, Cresswell JD. Research design. In: Qualitative, quantitative, and mixed methods approaches. Sage, 2018. 